\title{
ANÁLISIS Y COMENTARIOS SOBRE LA APLICACIÓN DE LOS INSTRUMENTOS PARA-ARANCELARIOS (IPAS) DURANTE EL GOBIERNO DE ALAN GARCÍA (1995-1990)
}

\section{Analysis and comments on the application of para-tariff instruments during the Government of Alan Garcia (1995-1990)}

Jorge Nicanor Arroyo Prado'

\section{RESUMEN}

A través de un análisis, en el presente trabajo, comentaremos la política de aplicación de instrumentos para-arancelarios (IPAS) que trabaron altamente las importaciones durante el gobierno de Alan García Pérez con el fin de proteger la industria nacional y las exigencias de los países sobre nuestras exportaciones.

Palabras clave: Instrumentos para-arancelarios (IPAS), protección verde o revolución verde

\begin{abstract}
Through an analysis, we made comments on the application policy of Para-tariff Instruments (IPAS), which heavily hampered imports, during the government of Alan García Pérez in order to protect the national industry and the demands of the countries to our exports.
\end{abstract}

Keywords: Para-tariff Instruments (IPAS), Green Protection or Green Revolution 


\section{ORIENTACIÓN ECONÓMICA DEL GOBIERNO CONSTITUCIONAL DEL PRESIDENTE ALAN GARCÍA PÉREZ}

Al inicio del periodo del presidente García, el Dr. Luis Alva Castro, en su libro Economía peruana 1985-1986: retos y respuestas [1, p. 29], presenta los objetivos, estrategias y políticas sectoriales del gobierno constitucional de ese entonces con los siguientes enunciados:

- Superar las precarias condiciones de vida de las clases populares, combatiendo el hambre y la desnutrición y, satisfaciendo en general, las necesidades básicas de la población a niveles compatibles con la dignidad humana.

- Transformar la estructura productiva a fin de compatibilizar las demandas sociales con la oferta interna de bienes y servicios esenciales y, de garantizar progresivamente el acceso a un empleo productivo.

- Modificar la situación de postergación y abandono del interior del país y de las áreas urbanomarginales dotándolos de los recursos necesarios para reducir la concentración económica en los núcleos modernos, priorizando el desarrollo de la sierra y el de los pueblos jóvenes.

- Transformar el Estado en un agente impulsor del desarrollo nacional, eficiente y planificador, con decidida vocación democrática antiimperialista, descentralizando su gestión de manera que permita dotar a los gobiernos locales y regionales con capacidad de decisión en todos los ámbitos de la actividad político-administrativa, pero sin perder la concepción unitaria de la República y el principio de autoridad democrática.

- Consolidar la democracia, sustentada en el pluralismo político-ideológico y en la diversidad de formas de organización empresarial, en el respeto a los derechos ciudadanos y en la búsqueda de la concertación social y la participación económica.

- Afirmar la soberanía y la defensa nacional y desarrollar una política exterior independiente y nacionalista basada en el no alineamiento, la solidaridad con el tercer mundo, la cooperación e integración andina y latinoamericana y el rechazo al injusto orden internacional imperante.

- Moralizar el país implantando un nuevo estilo ético en el ejercicio de la gestión pública y privada basado en la honradez y en la solidaridad nacional.

- Afirmar la identidad nacional y su forma cultural propia, concluyendo el proceso histórico de integración de nuestra pluralidad étnica con sus correspondientes valores espirituales.

- Restablecer el principio de la autoridad democrática, sobre la base del imperio de la justicia y la plena vigencia de la Constitución, Leyes y normas del Estado.

- Restituir la seguridad personal y la tranquilidad pública sustentada en la revolución en democracia y la eliminación de la violencia política.

El 1 de agosto de 1985, el Dr. Alan García Pérez se dirige a País y expone el programa de emergencia y las políticas sectoriales para el periodo 1985-1990, explicando los lineamientos generales que sustentan dichas políticas. Para efectos del presente trabajo de investigación, solo citaremos el segundo lineamiento, aquel que se refiere a la compatibilización del equilibrio externo con el crecimiento:

Ya hemos criticado exhaustivamente las políticas tradicionales orientadas a corregir el desequilibrio de la balanza de pagos, con sus consecuentes efectos recesivos por la contracción de la demanda interna y de las importaciones. Juzgamos entonces que es imprescindible, si pensamos en reactivación, un ajuste expansivo de la balanza de pagos fundado en el crecimiento de las exportaciones y la sustitución eficiente de las importaciones. No obstante, tomaremos en consideración que la viabilidad de ese ajuste expansivo está influida por el contexto internacional y, particularmente, por la mayor o menor facilidad que el Perú encuentre para incrementar sus exportaciones y captar recursos financieros externos . 
Continúa su exposición y más adelante dice: "Así mismo, dicho Ajuste Expansivo estará vinculado a la transformación de la estructura de producción favoreciendo tanto la sustitución de las importaciones (entre ellas alimentos, insumos y bienes para la producción), como las exportaciones que nos proporcionarán las divisas indispensables para el desarrollo" .

Asimismo, cuando expone su programa por sectores, menciona:

De acuerdo con el programa económico de emergencia, el sector comercio trabajará en base a los siguientes lineamientos:

- Garantizar el éxito de la actual (01.09.85) política de congelación de precios, para lo cual se vienen desarrollando acciones en los sectores empresariales y con la población en general, encontrando respuestas positivas en la cruzada contra la inflación. La creación de la Oficina de Defensa del Consumidor en los sectores es un importante paso en nuestras acciones contra la especulación y el acaparamiento.

- Desarrollar un eficiente sistema de promoción de exportaciones tradicionales que aumente los volúmenes actuales de exportación.

- Desarrollar un programa integral de expansión y promoción de exportaciones no tradicionales, superando la tendencia hacia los servicios aislados al exportador y el otorgamiento ciego y genérico del CERTEX y otros incentivos. Para ello debemos, entre otros aspectos, señalar que se dimensionará y racionalizará el sistema de las oficinas comerciales en el exterior a fin de lograr una más ágil y efectiva determinación de oportunidades de ventas al exterior y una activa promoción de exportaciones.

- Perfeccionar los criterios para el otorgamiento del Certex, haciendo más eficiente su administración, favoreciendo a quienes ofrezcan mayor valor agregado.

- Reforzar la capacidad negociadora de conjunto del país en el ámbito internacional haciendo un uso eficiente de la capacidad de compra del Estado con el objeto de obtener mejores condiciones de intercambio.

- Racionalizar nuestro sistema de comercio internacional adaptándolo a las nuevas prácticas de intercambio no convencional y delineando mecanismos para el desarrollo de las exportaciones a través del comercio compensado .

Dentro de este contexto, se propiciaría la búsqueda de nuevos instrumentos de promoción que tomaron en cuenta las normas internacionales de comercio. Las divisas iban a ser preferentemente orientadas hacia la importación de productos esenciales al consumo y a la producción, lo que iría a generar las condiciones que evitarían incrementar movimientos especulativos de precios en el mercado interno. Para ello, se usaron los siguientes instrumentos:

- Regulación de importaciones aplicable a los productos cuya producción interna sea necesario proteger o cuyo consumo sea prescindible.

- Continuar la revisión de los niveles arancelarios a fin de proteger selectivamente la producción interna. Asimismo, se evaluará la implicancia de las exoneraciones sectoriales sobre el nivel y estructura del arancel nacional.

\section{EVOLUCIÓN HISTÓRICA DEL COMERCIO EXTERIOR DURANTE EL PERÍODO 1985-1990}

En la esfera del comercio internacional, se observa la caída de los precios de los productos básicos de exportación debido a la recesión de los países desarrollados, al mismo tiempo que se elevan los precios de las manufacturas que importamos. Se configura, así, el resarcimiento a las economías dominantes del sistema de los efectos de las sucesivas alzas de los precios del petróleo, principalmente; pero, además, esos mismos países, violando las normas y principios del libre comercio internacional 
que promovieron y que nos siguen exigiendo, aplican diversas medidas proteccionistas que impiden nuestro acceso a sus mercados.

El deterioro de nuestro comercio exterior y el creciente servicio de la deuda externa han significado transferencias importantes de ingreso real, es decir, de parte de nuestro producto bruto interno hacia los países desarrollados. Dicho de otro modo, el agravamiento de nuestra pobreza es lo que en buena medida permite el mantenimiento de su riqueza. Pero, por si fuera poco, esta tendencia se ha visto agravada por la retracción simultánea del ingreso neto de capitales del exterior por concepto de nuevos créditos o inversiones directas (IED) acentuando la remesa de utilidades al extranjero, lo que ahonda el ciclo inevitablemente recesivo que se instauró en nuestro país, el desequilibrio de la balanza de pagos y el déficit fiscal [1, pp. 107-108].

Las necesidades propias de la reactivación productiva y de la alimentación de la población mantuvieron el valor de las importaciones. Incluso, en determinados períodos, aumentaron y obligaron a prestar una atención mayor al comercio exterior mediante la creación del Instituto de Comercio Exterior-ICE, con el objeto de centralizar las actividades vinculadas al comercio internacional y promoverlas, pero no cumplió con los objetivos de su creación.

Durante esta década, se incrementó considerablemente la violencia terrorista, conducida por los grupos alzados en armas (Sendero Luminoso y el MRTA), los que incidieron negativamente en el comportamiento de la economía peruana, y a los que se sumó el incremento del narcotráfico.

Teniendo en cuenta que el déficit de la balanza comercial es el principal responsable del déficit de la balanza en cuenta corriente del Perú, con relación a la brecha externa del segundo quinquenio de la década de los 80, Carlos Bolońa y Javier Illescas escriben lo siguiente:

El periodo 1985-1990 es mucho mejor conocido por todos. La brecha hasta 1988 estuvo asociada principalmente a un perfil creciente de brecha fiscal. En dicho año, el déficit en cuenta corriente respecto al PBI alcanzó a ser de 7.0\%, mientras que la brecha pública llegó a un pico de 9.3\%. Modificaciones poco profundas del manejo macroeconómico entre 1988 y 1989 dieron un respiro a la economía al cerrarse prácticamente la brecha externa en 1989. Sin embargo, esto se dio básicamente a través de la reducción de la inversión privada, ya que la brecha pública se mantuvo en niveles negativos de $8.4 \%$ y 6.4\% del PBI en los últimos ańos de gobierno [3, p. 17].

A julio de 1985, el Perú atravesaba por una alta crisis económica, que se manifestaba por una aceleración alarmante de la inflación y un deterioro del bienestar social. Para hacer frente a estos problemas, el Gobierno aprista decide cambiar la política económica: se pasó de una política económica parcialmente liberal y populista a otra de mayor protección de la economía nacional y con fuerte presencia del Estado en asuntos económicos y, para revertir la recesión productiva, se optó por ejecutar políticas monetarias y fiscales expansivas. Asimismo, se asumió un control de precios de los principales factores productivos (tipo de cambio, interés y salarios), así como de los bienes de primera necesidad. Para dicho propósito, se creó la Dirección General de Control de Precios.

Dicha política económica, fuertemente expansiva y controlista, dio lugar a manifestaciones del sector externo de la economía peruana. El resultado inmediato fue la reversión del saldo positivo de la balanza comercial, pues este pasó de \$1,219 millones en 1985 a \$-73 millones en 1986, y continuó el déficit comercial hasta 1988. Este déficit se originó fundamentalmente por el rápido incremento de las importaciones y no tanto por la disminución de las exportaciones (ver cuadro No 1). Este resultado era de esperar, teniendo en cuenta la naturaleza de nuestra estructura productiva fuertemente dependiente de bienes intermedios y de capitales importados. A esto habría que agregar el deterioro de los términos de intercambio que también incidió negativamente en el saldo de la balanza comercial.

Ante el incremento del déficit de la balanza comercial, el gobierno aprista optó por proteger el mercado interno. Para ello, recurrió al incremento de los aranceles, pues el arancel promedio pasó de 
57\% en 1984 a 63\% en 1985; luego, a 66\% en 1987, para después aumentarlo hasta $70 \%$ en 1988, lo que significó un incremento en más del doble del arancel promedio de 1981. También se impusieron instrumentos no arancelarios (IPAS) como las cuotas y las prohibiciones, pues en los años 1987 y 1988 el $90 \%$ de las partidas arancelarias estaban restringidas y el 10\% totalmente prohibidas, con $0 \%$ de las partidas de libre importación (ver cuadros No 1 y No 2). Estas medidas le otorgaron una alta protección al mercado interno con el objetivo de amortiguar el saldo negativo de la balanza comercial. Para este fin, se creó, en el ICE, una Comisión Especial de control de las importaciones. En ese entonces, el país no contaba con capitales externos suficientes para financiar dicho déficit, esto debido principalmente a la negativa del gobierno aprista a pagar la deuda externa peruana.

Si consideramos todo el periodo del gobierno aprista, según el cuadro No 03, observamos que el valor de las exportaciones aumentó a una tasa promedio anual de $1.6 \%$ y que el valor de las importaciones aumentó a una tasa de $9.9 \%$ anual, es decir, que las importaciones fueron mayores que las exportaciones. Por todas estas razones, el saldo de la balanza comercial se deterioró a la tasa promedio de $-8.3 \%$ anual, que evidentemente es una tasa de deterioro mayor a la de cualquier otro periodo de análisis considerado.

Como resultado de la política económica del gobierno aprista, el valor de las exportaciones respecto al PBI disminuyó drásticamente de $18.2 \%$ en 1985 a tan sólo $7.8 \%$ en 1987, para luego recuperarse levemente en los ańos subsiguientes; y el valor de las importaciones de lo que era $10.9 \%$ del PBI en 1985, bajó a 7.4\% en 1989. Estos resultados contribuyeron a que el valor del comercio exterior del Perú se debilitara aún más respecto al periodo anterior, pues dicho valor de lo que representaba el 29.1\% del PBI en 1985 pasó a ser $17 \%$ en 1987, para luego aumentar ligeramente en los dos ańos siguientes (ver cuadros $\mathrm{N}^{\circ} 5$ y $\mathrm{N}^{\circ}$ 6). Estos resultados reflejan el hecho de que, en este periodo, como consecuencia de la política proteccionista y aislacionista del régimen aprista, la economía peruana resultó menos abierta y poco insertada a la economía mundial. Debido a esto la balanza comercial se deterioró considerablemente, y estos hechos condujeron a la mayor crisis económica, social y política del Perú a fines de la década de los 80 con la inflación más alta de los últimos años.

CUADRO № 1. BALANZA COMERCIAL PERUANA 1985-1990 (EN MILLONES DE DÓLARES)

\begin{tabular}{cccc} 
Año & $\begin{array}{c}\text { Exportaciones } \\
\text { FOB }\end{array}$ & $\begin{array}{c}\text { Importaciones } \\
\text { FOB }\end{array}$ & Balanza Comercial \\
\hline 1985 & 3049 & 1830 & 1219 \\
\hline 1986 & 2576 & 2649 & -73 \\
\hline 1987 & 2715 & 3215 & -500 \\
\hline 1988 & 2731 & 2865 & -134 \\
\hline 1989 & 3533 & 2287 & 1246 \\
\hline 1990 & 3231 & 2922 & 399 \\
\hline
\end{tabular}

Fuente: Banco Central de Reserva-Memoria Anual 1985, 1986, 1987, 1988, 1989, 1990.

CUADRO NN 2. PERÚ: COMERCIO EXTERIOR POR PERÍODO (VARIACIÓN PORCENTUAL PROMEDIO ANUAL)

\begin{tabular}{cccc}
\hline Período & Exportaciones FOB & Importaciones FOB & Variación de la Balanza Comercial \\
\hline $1985-1990$ & 1.6 & 9.9 & -8.3 \\
\hline
\end{tabular}

Fuente: Banco Central de Reserva-Memoria Anual 1985, 1986, 1987, 1988, 1989, 1990 
CUADRO No 3. PERÚ: BALANZA COMERCIAL Y DETERMINANTES

\begin{tabular}{ccc}
\hline Año & Balanza Comercial (millones de US \$) & $\begin{array}{c}\text { Tasa de Arancel promedio a las } \\
\text { importaciones (\%) }\end{array}$ \\
\hline 1985 & 1219 & 63 \\
\hline 1986 & -73 & 63 \\
\hline 1987 & -500 & 66 \\
\hline 1988 & -134 & 70 \\
\hline 1989 & 1246 & 66 \\
\hline 1990 & 399 & 26 \\
\hline
\end{tabular}

CUADRO No 4. PERÚ: RESTRICCIONES PARA-ARANCELARIAS A LAS IMPORTACIONES (PARTICIPACIÓN DE ÍTEMS EN \%)

\begin{tabular}{cccccc}
\hline Año: Mes & $\begin{array}{c}\text { Importaciones } \\
\text { Libres }\end{array}$ & $\begin{array}{c}\text { Importaciones } \\
\text { Restringidas }\end{array}$ & $\begin{array}{c}\text { Importaciones } \\
\text { Prohibidas }\end{array}$ & $\begin{array}{c}\text { Importaciones } \\
\text { Prohib.Tempor. }\end{array}$ & $\begin{array}{c}\text { Universo } \\
\text { Arancel }\end{array}$ \\
\hline 1985-Julio & 90 & 7 & 0 & 3 & 100 \\
\hline 1985-Dic. & 61 & 29 & 10 & 0 & 100 \\
\hline 1986-Dic. & 91 & 29 & 10 & 0 & 100 \\
\hline 1987-Dic & 0 & 90 & 10 & 0 & 100 \\
\hline 1988-Dic & 0 & 90 & 10 & 0 & 100 \\
\hline 1989-Dic & 80 & 10 & 10 & 0 & 100 \\
\hline 1990-Jul & 90 & 0 & 10 & 0 & 100 \\
\hline 1990-Dic & 100 & 0 & 0 & 0 & 100 \\
\hline
\end{tabular}

Fuente: Banco Central de Reserva-Memoria Anual 1985, 1986, 1987, 1988, 1989, 1990

CUADRO N 5. PERÚ: COEFICIENTES DEL COMERCIO EXTERIOR (EN \%)

\begin{tabular}{ccccc} 
Año & $\begin{array}{c}\text { Exportaciones/ } \\
\text { PBI }\end{array}$ & $\begin{array}{c}\text { Importaciones/ } \\
\text { PBI }\end{array}$ & $\begin{array}{c}\text { Exportaciones } \\
\text { menos } \\
\text { Importaciones/ } \\
\text { PBI }\end{array}$ & $\begin{array}{c}\text { Exportaciones } \\
\text { más } \\
\text { Importaciones/ } \\
\text { PBI }\end{array}$ \\
\hline 1985 & 18.2 & 10.9 & 7.3 & 29.1 \\
\hline 1986 & 10.5 & 10.7 & -0.2 & 21.2 \\
\hline 1987 & 7.8 & 9.2 & -1.4 & 17.0 \\
\hline 1988 & 11.0 & 11.3 & -0.3 & 22.3 \\
\hline 1989 & 11.4 & 7.4 & 4.0 & 18.8 \\
\hline 1990 & 10.2 & 9.0 & 1.2 & 19.2 \\
\hline
\end{tabular}

Fuente: Banco Central de Reserva-Memoria Anual 1985, 1986, 1987, 1988, 1989, 1990 


\section{APLICACIÓN DE LOS INSTRUMENTOS PARA-ARANCELARIOS EN ESTE PERÍODO}

Mediante el Decreto Legislativo № 390 del 19 de setiembre de 1986, se crea el Instituto de Comercio Exterior-ICE, un organismo con rango ministerial dependiente del presidente de la República, constituido como persona jurídica de derecho público, con autonomía económica, técnica, financiera y administrativa y con patrimonio propio. Sus objetivos se orientaban a formular, ejecutar y supervisar la política de comercio exterior, así como a dirigir y coordinar todas las acciones que se realizaran para optimizar sus resultados. Como se mencionó anteriormente, este organismo no cumplió con sus fines de creación. A continuación, se describen los instrumentos para-arancelarios, que denominamos de segunda generación, más importantes que se aplicaron a través del ICE:

\section{- Licencias previas de importación}

Las licencias de importación son autorizaciones o permisos especiales que se dan como condición previa para importar un determinado producto. Constituyen un instrumento para regular y limitar el flujo y la cantidad de las importaciones. Inicialmente, fueron expedidsa por el Sector Industrias del Ministerio de Industria, Comercio, Turismo e Integración (MICTI), pero durante este Gobierno, el encargado de las funciones del ICE fue el Vice Ministerio de Comercio Exterior del Ministerio de Economía y Finanzas: en términos generales, los productos sujetos a licencia previa son aquellos que pueden importarse de acuerdo a la situación económica en que se encuentre el país, lo que equivale a reconocer que se tratan de importaciones controladas o requeridas por el Estado. Todos los sectores llamados productivos como industria, comercio, agricultura, pesquería, minería deberían contar con sus licencias previas, luego de trámites engorrosos del ICE. Existían productos regulados que excepcionalmente se trataban por:

a. Productos de importación prohibida

b. Productos sujetos a licencia previa de importación

\section{- Dictámenes de no competencia}

Las empresas importadoras estaban obligadas a publicar en el diario oficial El Peruano la relación de sus importaciones y luego, con dicha publicación, se solicitaba el dictamen de no competencia a la Dirección General de Industrias del Ministerio de Industria Comercio Turismo e Integración-MICTI. Esta oficina emitía dicho dictamen luego de verificar si no se encontraban inscritos los bienes a importar en el Registro de Productos Industriales Nacionales "RPIN" y de que no se hayan opuesto algunas empresas que producían dichos bienes en el país. El RPIN tenía el mismo carácter que el ex-Registro Nacional de Manufacturas.

\section{- Restricciones cuantitativas a las importaciones}

Dentro de las principales restricciones que se aplicaron, a través del ICE, se pueden destacar:

a. Cuotas: Eran los topes a la importación de un producto por un plazo determinado; pueden ser globales, selectivas por países o estacionales.

b. Prohibiciones: Las prohibiciones podían ser totales; se admitian excepciones a discreción del ICE o se aplicaban solo en ciertas condiciones.

c. Autorizaciones discrecionales y condicionales de importación: Las primeras se otorgaban a discreción del ICE y las segundas estaban condicionadas a que los importadores contraigan obligaciones en distintas esferas de la importación, por ejemplo, que se comprometieran a adquirir una cantidad equivalente de productos nacionales de la misma naturaleza con el objetivo de proteger la industria nacional. También podían ser subordinadas a condiciones 
específicas, como los resultados en materia de exportaciones o la ausencia de oferta nacional, tal y como se indicó anteriormente.

\section{- Certificado de Reintegro Tributario al producto No tradicional-CERTEX}

El rubro de reintegros tributarios que se otorgaban a través del título valor llamado CERTEX fue reestructurado por el Decreto Legislativo $\mathrm{N}^{\circ} 291$ y se aplicó en cinco modalidades:

a) Básico en niveles diferentes del 10 al 25\%

b) Descentralizado, que se adiciona al Básico un porcentaje único del 10\%

c) Artesanal, un porcentaje único del 35\%

d) Complementario, hasta un $10 \%$ para casos especiales

e) Adicional, un porcentaje único de $1 \%$ para Empresa Comercial de Exportación No Tradicional

En la aplicación del CERTEX para su otorgamiento, los porcentajes fijados se aplicaban sobre el valor FOB de la exportación, previa conversión de su valor en moneda extranjera a moneda nacional.

El gobierno del presidente Alan García elaboró su planteamiento económico sustentado en medidas económicas heterodoxas cuyos propósitos eran lograr una reactivación de la economía nacional y lograr que el aparato productivo, al activarse, se modernizara y atendiera las necesidades básicas del país.

Esta orientación suponía un liderazgo que sólo podría asumir el Gobierno, tomando el control del rol empresarial en todos sus aspectos. Juzgamos entonces que es imprescindible, si pensamos en reactivación, un ajuste expansivo de la balanza de pagos, basado en el crecimiento de las exportaciones y la sustitución eficiente de las importaciones. Es así que la viabilidad de ese ajuste expansivo está influida por el contexto internacional y, particularmente, por la mayor o menor facilidad que el Perú encuentre para incrementar sus exportaciones y captar recursos financieros externos.

Lo expresado en este mensaje, al ser aplicado durante su gestión gubernamental, no logró los resultados esperados de incrementar las exportaciones. Para facilitar este proceso de reactivación económica, era necesario que el sector empresarial privado trabajara junto con el Gobierno. Por ello, mientras se desarrollaba esta reactivación, mantuvieron todos sus privilegios, se perfeccionaron las protecciones legales y continuaron con el control del mercado nacional. Por las normas legales emitidas, se deduce que ellas formalizaron algunos IPAS para impedir las importaciones con el fin de mantener una protección vital a la industria manufacturera y al rol protagónico de las empresas públicas dedicadas a la exportación tradicional de productos (véase anexo $\mathrm{N}^{\circ} 1$ sobre dispositivos legales emitidos en este período).

Durante la actuación del ICE, se mantuvieron y se perfeccionaron algunas normas, pero las que se aplicaron desde periodos de gobierno anteriores no se tocaron, tales como normas de origen, normas técnicas a cargo de la Dirección General de Industrias, normas técnicas nacionales y los reglamentos técnicos a cargo del INTINTEC. Igual suerte corrieron las normas sanitarias, fitosanitarias y zoosanitarias.

\section{- Otros Instrumentos para-arancelarios identificados y aplicados durante este Gobierno}

Continuaron los certificados de origen, presupuestos de divisas, acuerdos bilaterales de comercio, listas de productos desgravados, cuota estacional de importación, compras del Gobierno. 


\section{PRINCIPALES PAÍSES RECEPTORES}

Durante el periodo 1985-1990, los destinos comerciales de las exportaciones peruanas continuaron teniendo como el principal socio comercial a los Estados Unidos, con un pequeńo incremento en el Mercado Común Europeo y luego con los doce países latinoamericanos agrupados en la ALADI (antes ALAC). Tanto el primero como el segundo destino seguían obteniendo por separado las mismas tendencias en cuanto a cifras del período anterior, el 29\% y el 25\% del total de las exportaciones en promedio.

Los países latinoamericanos agrupados en la ALADI, subdivididos en el Grupo Andino y Otros continuaron captando el 15\% de nuestras exportaciones. Con los países socialistas igualmente existía un lento intercambio comercial y con otros países (Asía, África y Oceanía) su nivel de captación llegó al $31 \%$.

Las orientaciones de las exportaciones peruanas siguieron manteniendo la entonces vigente comercialización donde $75 \%$ de exportaciones eran tradicionales y el $25 \%$ no tradicionales, a pesar de apoyarla con beneficios muy importantes. El destino de las Exportaciones FOB y el reflejo de los volúmenes comercializados muestran que no hay evidencia de tendencias crecientes. (ver cuadro № 6 )

CUADRO N ${ }^{\circ}$ 6. DESTINO DE LAS EXPORTACIONES FOB (MILLONES DE DÓLARES)

\begin{tabular}{|c|c|c|c|c|c|c|c|c|}
\hline \multirow[b]{2}{*}{ Años } & \multirow[b]{2}{*}{ USA } & \multirow[b]{2}{*}{ CANADA } & \multicolumn{3}{|c|}{ ALADI } & \multirow{2}{*}{$\begin{array}{l}\text { Mercado } \\
\text { Común } \\
\text { Europeo }\end{array}$} & \multirow{2}{*}{$\begin{array}{c}\text { Países } \\
\text { Socialistas }\end{array}$} & \multirow{2}{*}{$\begin{array}{l}\text { Otros } \\
\text { Países }\end{array}$} \\
\hline & & & $\begin{array}{c}\text { GRUPO } \\
\text { ANDINO }\end{array}$ & Otros & Total & & & \\
\hline 1985 & 947.0 & 28.6 & 249.8 & 152.8 & 402.6 & 854.2 & 153.3 & 663.3 \\
\hline 1986 & 631.6 & 17.6 & 145.8 & 176.7 & 322.5 & 697.5 & 98.2 & 808.6 \\
\hline 1987 & 633.0 & 47.0 & 157.0 & 205.8 & 362.8 & 756.4 & 66.6 & 849.2 \\
\hline 1988 & 579.1 & 21.9 & 149.7 & 123.8 & 273.5 & 881.6 & 25.4 & 949.5 \\
\hline 1989 & 713.4 & 26.7 & 151.4 & 235.7 & 387.1 & 785.4 & 120.1 & 1500.3 \\
\hline 1990 & 474.9 & 16.7 & 81.1 & 119.4 & 200.5 & 442.4 & 53.8 & 2042.7 \\
\hline
\end{tabular}

Fuente: Banco Central de Reserva-Memoria Anual 1985, 1986, 1987, 1988, 1989, 1990

\section{EVOLUCIÓN DEL PROCESO DE INTEGRACIÓN}

Las acciones relacionadas con el proceso de integración realizadas por el Gobierno de Alan García Pérez se concentraron en algunos aspectos importantes. Con el GRAN (hoy, CAN), se buscó su relanzamiento mediante la aprobación de un protocolo modificatorio del Acuerdo de Cartagena, buscando la actualización del Programa de Liberación, la utilización de las Cláusulas de Salvaguardia como mecanismo de excepción, la definición de normas que regulen las condiciones de competencia, el establecimiento de nuevas modalidades de desarrollo industrial, es decir, la diversificación como la agroindustria y la de bienes de capital.

En la Integración física y fronteriza mediante Convenios, podemos citar el proceso de facilitación administrativa y documentaria con Bolivia. El Perú participó en la I Reunión Preparatoria de la Rueda Regional de Negocios en Montevideo y en la Rueda Regional de Negociaciones Multilaterales en Buenos Aires, con el fin de redimensionar el papel de ALADI. De la misma manera, participó en la III Reunión Ordinaria del Comité de Acción de Seguridad Alimentaria Regional organizado por el SELA, así como en la I Sesión Ordinaria del Consejo Directivo de la OLDEPESCA dentro del marco del SELA. 


\section{COMENTARIOS AL PERÍODO.}

En el periodo 1985-1990, como consecuencia de las políticas económicas aplicadas por el gobierno de García Pérez, la importación de bienes intermedios tuvo mayor presencia mientras que la importación de bienes de capital disminuyó ligeramente, al igual que la importación de bienes de consumo.

Este período nos muestra algunas características del comercio exterior desarrollado por los actores implicados en esta actividad y podemos señalar aquellas causas estructurales y coyunturales que se presentaron durante este periodo. En cuanto los factores estructurales, podemos seńalar:

- Elevada concentración de nuestros productos de exportación en materias primas con precios bajos e inestables en el mercado internacional. En este periodo (1985-1990), las exportaciones de productos tradicionales concentraron un promedio del $75 \%$ del valor total exportado.

- Continuó la excesiva concentración del comercio exterior en pocos países. Esa situación generó una alta dependencia de nuestra economía nacional con respecto a la evolución económica de dichos países y limitó las posibilidades de colocación de nuestras exportaciones y el aprovisionamiento externo en mejores condiciones de intercambio.

- También existió contracción de las exportaciones tradicionales especialmente del petróleo crudo, cobre, harina de pescado, café, azúcar y hierro.

- Hubo incapacidad de la planta productiva interna para el desarrollo de una eficiente industria de exportación que posibilitara su crecimiento sostenido y sustituyera a las importaciones.

- Los niveles y composición de las importaciones, por la demanda y las características básicas de la estructura productiva nacional, mantuvo una elevada rigidez al continuar el sector industrial manufacturero altamente consumidor de materias primas, productos intermedios y de bienes de capital foráneos.

En cuanto a las causas coyunturales se pueden mencionar las siguientes:

- En este periodo, la capacidad de negociación comercial del Estado fue orientada por el Instituto de Comercio Exterior y ejecutada por las empresas públicas, buscando articular los objetivos tendientes a lograr el desarrollo comercial del país sin los logros esperados.

- Se mantuvo una estructura arancelaria que no respondió a los requerimientos de desarrollo del sector productivo, sino a circunstancias de carácter particular o de recaudación tributaria que demandó el sector empresarial privado para intervenir en este proceso.

- El comercio exterior peruano se caracterizó, en este periodo, por la aplicación de medidas políticas económicas con resultados similares al anterior Gobierno.

Se puede deducir que la creación del ICE no fue eficiente para la promoción y desarrollo del comercio exterior peruano al mantener una inadecuada estructura de protección arancelaria y continuar con la aplicación de instrumentos para-arancelarios (IPAS) que no se ajustaron a las necesidades y posibilidades del desarrollo industrial, la distorsión entre las prioridades industriales y la protección efectivamente otorgada y un complicado manejo administrativo que limitaba la agilidad en las operaciones de importación.

Se implantó el Registro de Productos Industriales Nacionales (RPIN) en el Ministerio de Industria, Comercio Exterior y Turismo, el que tuvo el mismo efecto de protección arancelaria que el Registro Nacional de Manufacturas (RNM), esto es, una protección de carácter infinita. 


\section{REFERENCIAS}

[1] L. Alva Castro, Economía Peruana 1985-1986- retos y respuestas. Lima; Perú: Instituto de Investigaciones Cambio y Desarrollo, 1987.

[2] E. G. Barreto, La globalización económica y el comercio internacional. Perú: Editorial La Pluma, 1996.

[3] C. Boloña Behr, Lecciones de Economía. Lima, Perú: Ed. IELM/USIL, 1999.

[4] C. Boloña y J. Illesca, Políticas Arancelarias en el Perú: 1980-1997. Lima, Perú: Ed. IELM/USIL, 1998.

[5] H. Bryant y S. Mehrtenst, La Cuarta Ola: El mundo de los negocios en el siglo XXI. BarcelonaEspaña: Edit. Gráfica, 1996.

[6] D. Brean y M. Glave, Recursos naturales y desarrollo: un diálogo canadiense-latinoamericano. Perú: Edit. Atenea, 2000.

[7] R. Carranza Noriega. Medioambiente: Problemas y soluciones. Perú: Universidad Nacional del Callao, 2001.

[8] J. Cascio, G. Woodside, y P. Mitchell. Guia ISO 14000: Las nuevas normas internacionales para la Administración Ambiental. Mc Graw-Hill Interamericana Editores, 1997.

[9] CONAM, Marco estructural de Gestión Ambiental. Lima, Perú: Consejo Nacional del Ambiente, 1999.

[10] E. Cornejo Ramírez, Comercio Internacional: hacia una gestión competitiva. Lima, Perú: Editorial San Marcos, 1996.

[11] H. De Soto, El misterio del capital. Lima, Perú: Editorial de El Comercio, 2000.

[12] BCR, Banco Central de Reservas del Perú. [En línea]. Disponible en: www.bcrp.gob.pe. [Accedido: 27-jul-2018]

[13] CEPAL, Comisión Económica para América Latina y El Caribe. [En línea]. Disponible en: www.cepal.org. [Accedido: 30-jul-2018]

[14] Confederación General de Trabajadores de España. [En línea]. Disponible en: www.cgt.es/. [Accedido: 12-set-2018]

[15] Centro de Comercio Internacional. [En línea]. Disponible en: www.cideiber.com. [Accedido: 12-set-2018]

[16] Sociedad de Comercio Exterior del Perú. [En línea]. Disponible en: www.comexperu.org.per. [Accedido: 21-jul-2018]

[17] Comunidad Andina. [En línea]. Disponible en: www.comunidadandina.org. [Accedido: 21-jul-2018]

[18] CONAM, Consejo Nacional del Ambiente. [En línea]. Disponible en: www.conam.gob.pe. [Accedido: 12-jul-2018] 